CLINICAL STUDY

\title{
Visceral adipose tissue zinc finger protein 36 mRNA levels are correlated with insulin, insulin resistance index, and adiponectinemia in women
}

\author{
Luigi Bouchard ${ }^{1,2,3}$, Marie-Claude Vohl ${ }^{1,2,3}$, Yves Deshaies ${ }^{4}$, Caroline Rhéaume ${ }^{5}$, Marleen Daris ${ }^{5}$ \\ and André Tchernof ${ }^{2,3,6}$ \\ ${ }^{1}$ Lipid Research Center, ${ }^{2}$ Nutraceuticals and Functional Foods Institute, ${ }^{3}$ Department of Food Science and Nutrition, ${ }^{4}$ Department of Anatomy and \\ Physiology and Laval Hospital Research Center, ${ }^{5}$ Gynecology Unit, CHUQ Pavilion CHUL, and ${ }^{6}$ Molecular Endocrinology and Oncology Research Center, \\ Laval University Medical Research Center, Laval University, Québec, Canada \\ (Correspondence should be addressed to A Tchernof; Email: andre.tchernof@crchul.ulaval.ca)
}

\begin{abstract}
Introduction: Adipose tissue is now recognized as an endocrine organ and secretes numerous molecules and proteins potentially involved in the physiopathology of the metabolic syndrome. Recently, we have determined the transcriptome of omental adipose tissue, leading to the identification of a new candidate gene for obesity-related metabolic complications, zinc finger protein 36 (ZFP36), which is known to down-regulate tumor necrosis factor- $\alpha(T N F-\alpha)$ expression.

Objective: The objective of this study was to further examine the relationship between ZFP36 gene expression levels, obesity-related phenotypes, and adipokines.

Methods: Abdominal subcutaneous and omental adipose tissue samples were obtained from 46 women undergoing elective gynecological surgery. Adipose tissue ZFP36 mRNA abundance was assessed by quantitative real-time PCR. Body fat accumulation and distribution were measured by dual X-ray absorptiometry and computed tomography. Fasting blood levels of glucose, insulin, and lipids, and circulating TNF- $\alpha$, interleukin- 6 (IL-6), resistin, and adiponectin were also measured.

Results: No correlation was observed between s.c. ZFP36 mRNA levels and any of the phenotypes tested. However, although omental ZFP36 mRNA levels were not correlated with measures of body fatness and lipid profile, they were negatively correlated with fasting insulin levels $(R=-0.31 ; P=0.05)$, the insulin resistance index (HOMA-IR; $R=-0.31 ; P=0.05)$, and 2 -h post-glucose insulinemia $(R=-0.32$; $P=0.05)$. Omental ZFP36 mRNA abundance was also positively correlated with adiponectinemia $(R=$ $0.35 ; P=0.03)$ but not with circulating TNF- $\alpha$, IL- 6 , and resistin concentrations.

Conclusion: These results suggest that ZFP36 gene expression in omental adipose tissue, but not in abdominal s.c. fat, may offer partial protection against the development of insulin resistance and diabetes.

European Journal of Endocrinology 157 451-457
\end{abstract}

\section{Introduction}

Obesity is associated with several risk factors for type 2 diabetes and cardiovascular disease, two conditions associated with high morbidity and mortality rates (1). These risk factors, which define the metabolic syndrome, include hyperglycemia, dyslipidemia, hypertension, abdominal/visceral obesity, and a prothrombotic/proinflammatory state (2). Adipose tissue is now recognized as an important endocrine organ secreting numerous molecules and proteins potentially involved in the physiopathology of the metabolic syndrome (3). Indeed, the identification and characterization of novel adipose tissue-expressed genes and proteins are likely to provide further insight into its endocrine function and its relationship with the development of the metabolic syndrome.
Recently, the transcriptome of abdominal visceral (omental) adipose tissue in obese men with and without the metabolic syndrome was established to propose new metabolic syndrome candidate genes. This strategy led to the identification of zinc finger protein 36 (ZFP36) as a candidate gene related to obesity complications (4). The ZFP36 gene was found to be 4.6-fold overexpressed in obese men without the metabolic syndrome, suggesting that it may be related to a protective effect against the development of obesity-related metabolic complications (4). Furthermore, two ZFP36 polymorphisms were associated with body weight, body mass index (BMI), as well as glucose and LDL-cholesterol levels in a cohort of 709 severely obese men and women. Some of these associations were found only in men (glucose) and some only in women (body weight and BMI), suggesting that ZFP36 
may have sex-specific effects. Moreover, these two polymorphisms accounted for $10.1 \%$ of the variance in ZFP36 mRNA levels in omental adipose tissue of non-diabetic premenopausal women (4). The ZFP36 protein has been discovered when searching for genes that were activated by insulin (5) and has been associated, in knockout animals, with a complex inflammatory syndrome due to increased circulating levels of the inflammatory response mediator tumor necrosis factor- $\alpha(\mathrm{TNF}-\alpha)(6,7)$. Given that the metabolic syndrome is associated with increased circulating TNF- $\alpha$ and a chronic inflammation state (8), our previous results on the ZFP36 gene and its physiological role suggest that it may be involved in the physiopathology of obesity-related metabolic complications.

Therefore, the present study was aimed at investigating, in women covering a wide range of adiposity, the potential relationship between ZFP36 gene expression levels in abdominal s.c. or omental adipose tissues and body fat accumulation and distribution, fasting blood glucose, insulin, lipids, and a number of circulating inflammatory adipokines (TNF- $\alpha$, interleukin-6 (IL-6), resistin, and adiponectin) concentrations. Given the postulated protective role of ZFP36 against the development of obesity-related metabolic complications, we tested the hypothesis that low adipose tissue ZFP36 mRNA abundance would be correlated with an altered metabolic profile including hyperglycemia, dyslipidemia, and a proinflammatory state.

\section{Research methods and procedures}

\section{Subjects}

A total of 46 women undergoing elective surgery were recruited through the Gynecology Unit of the Laval University Medical Center. These women elected for total $(n=45)$ or subtotal $(n=1)$ abdominal hysterectomies, some with salpingo-oophorectomy of one $(n=8)$ or two $(n=17)$ ovaries for one or more of the following reasons: menorrhagia/menometrorrhagia $(n=24)$, myoma/fibroids $(n=32)$, incapacitating dysmenorrhea $(n=8)$, pelvic pain $(n=1)$, benign cyst $(n=10)$, endometriosis $(n=7)$, adenomyosis $(n=1)$, pelvic adhesions $(n=4)$, endometrial hyperplasia $(n=3)$, or polyp $(n=2)$ and ovarian thecoma $(n=1)$. Apart from their gynecological condition, participants were in general good health, with normal kidney and liver function. All patients were free from autoimmune diseases or long-term diabetes complications. One patient was diagnosed with type 2 diabetes at the time of study. Patients were not taking medication possibly affecting insulin sensitivity. Five women reported the use of synthroid. Menopausal status was established using menstrual history questionnaire, medical files, and plasma follicle-stimulating hormone levels. A total of 23 women were premenopausal, 7 were perimenopausal, and 9 were menopausal. The medical ethics committees of Laval University and Laval University Medical Center approved this study. Written informed consent was obtained from all subjects before their inclusion in the study.

Body weight, height, and resting blood pressure (systolic and diastolic) were measured preoperatively using standardized procedures as previously described (9). Body fat mass and body fat distribution were determined on the morning of, or a few days before or after the surgery. Total body fat mass, fat percentage, and fat-free mass were determined by dual energy X-ray absorptiometry using a Hologic QDR-2000 densitometer and the enhanced array whole-body software V5.73A (Hologic Inc., Bedford, MA, USA). L4-L5 s.c. and visceral adipose tissue areas were determined by computed tomography as previously described (10) using a GE Light Speed 1.1 CT scanner (General Electric Medical Systems, Milwaukee, WI, USA). The Image J $1.33 \mu$ software (National Institutes of Health, Bethesda, MD, USA) was used to quantify visceral adipose tissue areas by delineating the intraabdominal cavity at the internal-most aspect of the abdominal and oblique muscle walls surrounding the cavity and the posterior aspect of the vertebral body. Adipose tissue was highlighted and computed using an attenuation range of -190 to -30 Hounsfield units. The coefficients of variation between two measures from the same observer $(n=10)$ were $0.0,0.2$, and $0.5 \%$, for total, s.c., and visceral adipose tissue areas respectively.

On the morning of surgery, 12-h fasting blood samples were obtained to measure cholesterol and triglyceride levels in plasma and lipoprotein fractions by using a Technicon RA-analyzer (Bayer Corp Inc.), as previously described (11). Plasma VLDL were isolated by ultracentrifugation, and the HDL fraction was obtained by precipitation of the LDLs from the infranatant with heparin and $\mathrm{MnCl}_{2}$ (12). The concentration of LDLcholesterol was computed by subtraction of cholesterol levels of the infranatant measured before and after precipitation. Plasma glucose was measured using the glucose oxidase method and plasma insulin levels were measured by RIA (within-assay precision: $\mathrm{CV} \leq 6.0 \%$; Linco Research, St Charles, MO, USA). The HOMA insulin resistance index was calculated using fasting insulin $(\mu \mathrm{U} / \mathrm{ml}) \times$ fasting glucose $(\mathrm{mmol} / \mathrm{l}) / 22.5$ and was used to estimate insulin sensitivity in the fasting state (13). Finally, plasma TNF- $\alpha$ (within-assay precision: CV $\leq 8.8 \%$ ), IL-6 (within-assay precision: $\mathrm{CV} \leq 7.8 \%$; R\&D Systems, Minneapolis, MN, USA), and resistin (within-assay precision: $\mathrm{CV} \leq 7.0 \%$; Linco Research) levels were measured by ELISA and plasma adiponectin levels were measured by RIA (within-assay precision: $\mathrm{CV}=6.2 \%$; Linco Research).

An oral glucose tolerance test was performed a few days before ( 9 women) or after (33 women) the 
surgery. Women were given $75 \mathrm{~g}$ oral glucose after a 12-h overnight fast. A blood sample was obtained from an antecubital vein at $2 \mathrm{~h}(120 \mathrm{~min})$ for glucose and insulin determinations.

\section{Adipose tissue sampling}

S.c. adipose tissue was collected at the site of surgical incision (lower abdomen) and omental adipose tissue was collected from the distal portion of the greater omentum (epiploon). Samples were collected during the surgical procedure and immediately carried to the laboratory in $0.9 \%$ saline preheated at $37^{\circ} \mathrm{C}$, and were immediately frozen in liquid nitrogen and stored at $-80{ }^{\circ} \mathrm{C}$ for subsequent analyses. S.c. and visceral adipose tissues were sampled from each individual, but one sample was missing from one of the fat depots for two different women. Thus, although 46 women were included in the study, only 44 adipose tissues from each depot were included in the analyses.

\section{ZFP36 measurements}

Total RNA was isolated from $\sim 150 \mathrm{mg}$ omental or s.c. adipose tissue using RNeasy lipid tissue extraction kit (Qiagen) following the manufacturer's recommendations. On-column digestion of DNA with RNase-free DNase set (Qiagen) was used to efficiently remove traces of DNA. RNA quantity and quality were assessed using an Agilent Technologies 2100 bioanalyzer and RNA 6000 Nano LabChip kit (Agilent, Mountain View, CA, USA). cDNA was generated from $40 \mathrm{ng}$ total RNA using $1.4 \mu \mathrm{g}$ total purified RNA with Invitrogen Superscript II. RNA was denatured over $5 \mathrm{~min}$ at $65^{\circ} \mathrm{C}$ with $350 \mathrm{ng}$ random hexamers (Invitrogen) and 35 nmoles dNTP (Amersham Biosciences) in a volume of $42 \mu \mathrm{l}$. The solution was chilled for 5 min on ice and mixed (final volume of $70 \mu \mathrm{l}$ ) with first strand buffer, dithiothreitol and 300 units of Superscript II (Invitrogen) following the manufacturer's recommendations. After $10 \mathrm{~min}$ at room temperature, reaction vessels were incubated at $42{ }^{\circ} \mathrm{C}$ for $120 \mathrm{~min}$. Equal amounts of cDNA were run in triplicate and amplified in a $15 \mu \mathrm{l}$ reaction containing $7.5 \mu \mathrm{l} 2 \mathrm{X}$ Universal PCR Master Mix (Applied Biosystems, Foster City, CA, USA), $10 \mathrm{nM}$ Z-tailed forward primer, $100 \mathrm{nM}$ reverse primer, $100 \mathrm{nM}$ Amplifluor Uniprimer probe (Chemicon, Temecula, CA, USA), and $2 \mu \mathrm{l}$ DNA target. No-template controls were used as recommended. The mixture was incubated at $50{ }^{\circ} \mathrm{C}$ for $2 \mathrm{~min}$, at $95^{\circ} \mathrm{C}$ for $4 \mathrm{~min}$, and then cycled at $95^{\circ} \mathrm{C}$ for $15 \mathrm{~s}$ and at $55^{\circ} \mathrm{C}$ for $40 \mathrm{~s} 55$ times using the Prism 7900 Sequence Detector (Applied Biosystems). Amplification efficiencies were validated and normalized to ribosomal $18 \mathrm{~S}$ and quantity of target gene was calculated according to a standard curve. $18 \mathrm{~S}$ is an established and accepted reference gene (14). Our own experience showed that it is comparable with other reference genes including LRP1O, CLN3, and HPCAL1 (data not shown). Primer sequences were designed using Primer Express 2.0 (Applied Biosystems) and were the following: 5'-Ztail-GGCCAACCGTTACACCATG-3', 5'-CGACAGGAGGCTCTCGTAGATG-3' (ZFP36) and 5'-Ztail-TGCATGTCTAAGTACGCACGG-3', 5'-AATGAGCCATTCGCAGTTTCA-3' (18S). Forward primers containing the $5^{\prime} \mathrm{Z}$ sequence: ACTGAACCTGACCGTACA were used to detect amplicons with the Amplifuor UniPrimer system. PCR data are expressed in arbitrary units (18S rRNA-normalized).

\section{Statistical analysis}

Mean ZFP36 mRNA expression differences between s.c. and omental adipose tissue were tested using a paired $t$-test and correlations between s.c. and omental ZFP36 mRNA levels and adiposity, lipid and glucose-related variables and adipokines were tested using (partial) Pearson and Spearman rank correlation coefficients. The contribution of abdominal fat area, metabolic syndrome, and menopausal status as covariates in correlations was tested using multiple regression analyses. Transformations were applied to nonnormally distributed variables (square root: HOMA-IR, 2-h post-glucose glycemia and insulinemia; and logarithm: systolic blood pressure, glucose, resistin, IL-6, and omental ZFP36 mRNA levels) to meet Pearson correlation statistical assumptions. To be considered as affected by the MS, women had to fulfill at least three of the risk factors described in the NCEP-ATP III (15). Since the waist girth measure was not available in the present study, a cutoff value of $100 \mathrm{~cm}^{2}$ for visceral adipose tissue area (16) was used instead of a waist girth of $88 \mathrm{~cm}$. Analyses were performed using SAS software, version 8.02 (SAS Institute Inc., Cary, NC, USA).

\section{Results}

Table 1 presents the physical characteristics of women included in this study. These women were, on average, 47.3 years old, overweight according to their mean BMI and had a normal lipid profile and glucose metabolism according to current clinical guidelines (17). However, they covered a wide range of adiposity $\left(19.1-41.3 \mathrm{~kg} / \mathrm{m}^{2}\right)$ and seven $(18 \%)$ of them were characterized by the metabolic syndrome (15).

Substantial variation was found for adipose tissue ZFP36 mRNA levels in women, and mRNA abundance in s.c. adipose tissue showed a near twofold higher level when compared with omentum (Table 1). Moreover, ZFP36 mRNA levels were approximately twofold lower in the subgroup of women with the metabolic syndrome $(13.79 \pm 8.27$ vs $24.94 \pm 4.00 ; P=0.15)$ when compared with women without the metabolic syndrome.

In s.c. adipose tissue, none of the correlations tested between ZFP36 mRNA levels and the phenotypes under 
Table 1 Physical characteristics of the study women.

\begin{tabular}{|c|c|c|}
\hline & Mean \pm s.D. $(n)$ & Range \\
\hline Age (years) & $47.3 \pm 5.0(46)$ & $39.6-61.7$ \\
\hline BMl $\left(\mathrm{kg} / \mathrm{m}^{2}\right)$ & $27.7 \pm 5.2(46)$ & $19.1-41.3$ \\
\hline Body fat mass $(\mathrm{kg})$ & $26.5 \pm 9.7(46)$ & $11.2-50.8$ \\
\hline S.c. adipose tissue area $\left(\mathrm{cm}^{2}\right)$ & $344 \pm 149(44)$ & $103-759$ \\
\hline Visceral adipose tissue area $\left(\mathrm{cm}^{2}\right)$ & $102 \pm 50(44)$ & $34-233$ \\
\hline Fasting glucose $(\mathrm{mM})$ & $5.65+0.55(42)$ & $4.80-7.80$ \\
\hline Fasting insulin (pM) & $11.66 \pm 5.70(42)$ & $3.37-27.64$ \\
\hline HOMA-IR & $3.02 \pm 1.74(42)$ & $0.77-8.85$ \\
\hline 2-h post-glucose glycemia (mM) & $6.62 \pm 1.80(42)$ & $4.00-14.80$ \\
\hline 2-h post-glucose insulinemia (pM) & $66.03 \pm 36.79(42)$ & $11.35-143.33$ \\
\hline Triglycerides $(\mathrm{mM})$ & $1.32 \pm 0.65(43)$ & $0.51-2.99$ \\
\hline Total cholesterol (mM) & $4.85 \pm 0.60(43)$ & $3.55-5.95$ \\
\hline HDL-cholesterol (mM) & $1.44+0.33(43)$ & $0.81-2.14$ \\
\hline LDL-cholesterol (mM) & $2.81 \pm 0.51(43)$ & $1.50-3.96$ \\
\hline Systolic blood pressure $(\mathrm{mmHg})$ & $129.4 \pm 15.0(46)$ & $105.0-188.0$ \\
\hline Diastolic blood pressure $(\mathrm{mmHg})$ & $75.7 \pm 9.5(46)$ & $49.0-92.0$ \\
\hline TNF- $\alpha(\mathrm{pg} / \mathrm{ml})$ & $1.24 \pm 0.50(41)$ & $0.68-3.18$ \\
\hline IL-6 (pg/ml) & $2.41+2.00(42)$ & $0.73-12.60$ \\
\hline Resistin (ng/ml) & $23.90 \pm 6.40(42)$ & $14.02-48.34$ \\
\hline Adiponectin (ng/ml) & $47.35 \pm 22.4(42)$ & $1.56-103.37$ \\
\hline S.c. ZFP36 mRNA abundance ${ }^{a}$ & $39.31 \pm 28.9(44)$ & $2.06-119.44$ \\
\hline Omental ZFP36 mRNA abundance ${ }^{a}$ & $21.33+20.62(44)$ & $1.67-117.54$ \\
\hline
\end{tabular}

$n$, number of women

a 18S-normalized.

study were statistically significant (Table 2). However, trends for positive associations between s.c. ZFP36 mRNA levels and plasma triglyceride and resistin concentrations were found (Table 2).

ZFP36 mRNA abundance in omental adipose tissue was negatively correlated with fasting insulin, the HOMA-IR index, and 2-h post-glucose insulinemia and positively correlated with adiponectinemia (Table 2 and Fig. 1). In other words, higher levels of ZFP 36 mRNA in omental adipose tissue were associated with a lower fasting insulin level and lower HOMAassessed insulin resistance (or higher insulin sensitivity) and with higher plasma adiponectin concentrations. Spearman correlation coefficients were consistent with the results described above (data not shown). Moreover, abdominal visceral fat area, metabolic syndrome, and menopausal status, when included in the regression models as covariates, did not show a significant contribution $(P \geq 0.05)$ to the correlation between omental ZFP36 mRNA levels and fasting insulin, HOMA-IR, 2-h post-glucose insulinemia, and adiponectinemia (data not shown). None of the other variables tested showed significant correlations with omental ZFP36 mRNA levels (Table 2).

The correlations between adiponectinemia and risk factors for type 2 diabetes are well known and were also tested. As expected, adiponectinemia was significantly correlated or showed a trend for significant correlations with many of the features of the metabolic syndrome such as BMI $(R=-0.290 ; P=0.06)$, fat mass $(R=-0.307$; $P=0.05)$, s.c. $(R=-0.293 ; P=0.07)$, and visceral $(R=-0.426 ; P=0.006)$ adipose tissue areas, fasting glucose $(R=-0.292 ; P=0.06)$, HOMA-IR $(R=-0.268$;
$P=0.09), 2$-h post-glucose insulinemia $(R=-0.294$; $P=0.07)$, HDL-cholesterol $(R=0.464 ; P=0.002)$, and LDL-cholesterol $(R=-0.438 ; P=0.004)$. Contrary to correlations with omental ZFP36 mRNA levels,

Table 2 Pearson correlation coefficients $(R)$ between adipose tissue zinc finger protein 36 (ZFP36) mRNA levels and adiposity and metabolism-related phenotypes and adipokines.

\begin{tabular}{lcc}
\hline & $\begin{array}{c}\text { s.c. AT ZFP36 } \\
\text { mRNA levels }(R)\end{array}$ & $\begin{array}{c}\text { Omental AT ZFP36 } \\
\text { mRNA levels }(R)\end{array}$ \\
\hline BMI & 0.146 & -0.119 \\
Body fat mass & 0.085 & -0.110 \\
s.c. adipose tissue & 0.174 & -0.061 \\
$\quad$ area & 0.102 & -0.185 \\
Visceral adipose & & \\
$\quad$ tissue area & 0.131 & -0.204 \\
Fasting glucose & -0.061 & $-0.310^{\star}$ \\
Fasting insulin & -0.027 & $-0.314^{*}$ \\
HOMA-IR & 0.047 & -0.200 \\
2-h post-glucose & & \\
$\quad$ glycemia & -0.010 & $-0.315^{\star}$ \\
2-h post-glucose & & \\
insulinemia & $0.287^{\dagger}$ & -0.146 \\
Triglycerides & 0.162 & -0.064 \\
Total cholesterol & -0.111 & 0.084 \\
HDL-cholesterol & 0.090 & -0.044 \\
LDL-cholesterol & 0.220 & 0.019 \\
Systolic blood & & \\
pressure & -0.060 & -0.021 \\
Diastolic blood & & \\
$\quad$ pressure & & 0.146 \\
TNF- $\alpha$ & 0.114 & -0.052 \\
IL-6 & 0.197 & 0.148 \\
Resistin & $0.283^{\dagger}$ & $0.350^{\star}$ \\
Adiponectin & 0.064 & \\
\hline & &
\end{tabular}

$\mathrm{AT}$, adipose tissue; OGTT, oral glucose tolerance test; ${ }^{\dagger} 0.08 \geq P>0.05$; and ${ }^{*} P \leq 0.05$. 

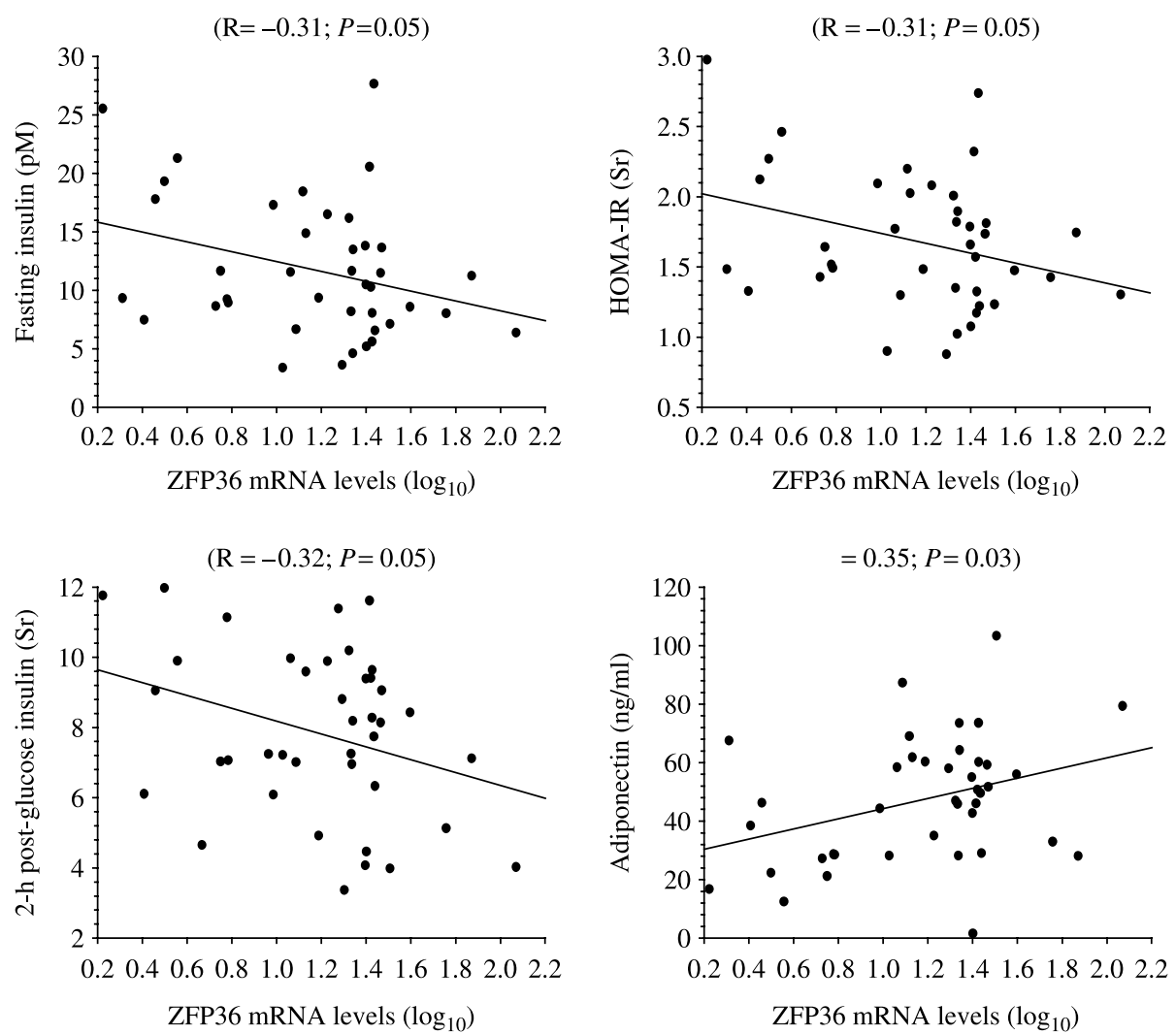

Figure 1 Pearson correlations between glucose metabolismrelated phenotypes and omental adipose tissue ZFP36 mRNA levels. Sr, square root. abdominal visceral fat area, when included in the regression models as a covariate, contributed significantly $(P \leq 0.05)$ to correlations between adiponectinemia and fasting glucose, HOMA-IR, and HDL-cholesterol and LDLcholesterol but not for fat mass, HOMA-IR, 2-h postglucose insulinemia, and HDL-cholesterol $(P$ values for visceral fat contribution to the models: $0.09>P>0.05)$. Overall, only plasma HDL-cholesterol $(R=0.408$; $P=0.01)$ and LDL-cholesterol levels $(R=-0.375$; $P=0.02$ ) remained significantly correlated with adiponectinemia after the latter adjustment.

\section{Discussion}

Although expression and association studies had suggested that ZFP36 may be a candidate gene for obesity-related metabolic complications in severely obese men and women (4), no compelling evidence existed to support its association with these conditions. Moreover, results of our original study suggested that ZFP36 might have different effects on the cardiovascular disease risk profile in men and women (4). Here, the relationship between adipose tissue ZFP36 mRNA levels and adiposity, metabolic variables, and adipokines was investigated in women. To our knowledge, this is the first study to examine ZFP36 expression in adipose tissue compartments and to link it with features of the metabolic syndrome.

ZFP36 mRNA levels in s.c. and omental adipose tissues were also previously assessed in non-diabetic, severely obese men (18). In that study, although subjects were severely obese $\left(\mathrm{BMI}>40 \mathrm{~kg} / \mathrm{m}^{2}\right)$, they were not diabetic and had, on average, a normal lipid profile based on the NCEP-ATPIII criteria for the metabolic syndrome (15). However, as opposed to the present study, ZFP36 mRNA levels were increased (3.7fold) in omental versus s.c. adipose tissue. This difference may reflect a sex-specific difference or a variable lability to cellular stimuli of ZFP36 gene expression, depending on the level of adipose tissue insulin sensitivity. This discrepancy could also be attributed to population differences in adipose tissue cell composition.

The ZFP36 protein was discovered about 15 years ago in an attempt to identify genes that were activated by insulin (5). Its expression was found to be highly and transiently responsive to insulin in many cell types including mouse cultured fibroblasts overexpressing human insulin receptors (NIH 3T3 HIR3.5) (19), mouse 3T3-L1 adipocytes, and mouse adipose tissue (adult male BALB/c) (5). In the present study, omental ZFP36 mRNA levels were negatively correlated with plasma insulin and markers of insulin sensitivity such as HOMA-IR, and positively correlated with circulating 
concentration of adiponectin, an adipokine produced by adipocytes that is negatively regulated by insulin and proposed to act as an insulin sensitizer (20). These apparently conflicting observations may reflect species differences in ZFP36 expression regulation, as previously suggested (5) or may reflect a certain level of insulin resistance in women with higher fasting insulin concentrations and in severely obese men with the metabolic syndrome (4). Lai et al. have shown that the ZFP36 gene promoter and intron 1 harbor known and novel transcription factor-binding sites $(21,22)$, suggesting that ZFP36 expression is tightly regulated. Interestingly, s.c. ZFP36 mRNA levels were not correlated with glucose homeostasis variables, nor with its level in omental adipose tissue, which also suggests that ZFP36 expression is highly regulated and sensitive to different stimuli in different tissues. However, although its response to insulin exposure in human and the transcription factors involved in its expression in adipocytes still remain to be established (23), it is expected that insulin modulates ZFP36 expression.

ZFP36 gene knockout mice allowed determination of at least one of its potential physiological roles $(6,7)$. The results of these studies suggested that ZFP36 is involved in TNF- $\alpha$ post-translational regulation, through destabilization of its mRNA by binding AU-rich elements (AUUUA) located in TNF- $\alpha 3^{\prime}$ UTR $(6,7)$. This led to a complex inflammatory syndrome associated with an increased level of circulating TNF- $\alpha(6,7)$. TNF- $\alpha$ is produced by many cell types including those located in adipose tissue and is now recognized to induce, directly and indirectly, insulin resistance in humans and other species (24). However, in the present study, ZFP36 mRNA levels were not correlated with circulating TNF- $\alpha$ concentration as well as omental TNF- $\alpha$ mRNA abundance (barely detectable by real-time PCR in the few samples tested, data not shown). These results suggest that its association with glucose metabolism can be independent of TNF- $\alpha$ gene expression dysregulation and circulating levels of the cytokine.

ZFP36 is also known to decrease mRNA stability of a few other inflammatory transcripts (GMCSF, IL-3, and COX-2 genes) (25). Adiponectin is not currently one of its known targets, but since ZFP 36 and adiponectin are both expressed in adipocytes $(5,26)$ and since adiponectin shares structural and sequence homology with TNF- $\alpha$ and has an anti-inflammatory function (27), it could be possible that ZFP36 interacts directly with adiponectin mRNA. However, although the adiponectin transcript harbors four AU-rich elements in its $3^{\prime}$ UTR, this may not necessarily be the case. ZFP36 mRNA levels and circulating adiponectin concentrations were positively correlated in the present study, although ZFP36 supposedly would destabilize target gene mRNAs. Moreover, the correlations between ZFP36 and adiponectin mRNA levels in omental and s.c. adipose tissue were not significant (data not shown).
Thus, whether ZFP36 modulates adiponectin expression at the post-transcriptional level still needs to be determined.

It is also important to point out that, in contrast to correlations of insulin and adiponectin with adiposity and lipid-related phenotypes, the correlations observed with omental ZFP36 mRNA levels were independent of body fatness, suggesting that ZFP36 is less likely than insulin and adiponectin to be 'dysregulated' in obesity per se, potentially offering a new therapeutic avenue for insulin resistance and diabetes. This observation is also in agreement with the results of our previous study from which ZFP36 was proposed as new candidate gene for metabolic complications independently of obesity (4).

In summary, omental ZFP36 mRNA level was correlated with fasting insulin, HOMA-IR, and adiponectinemia, which indirectly suggests a role for ZFP36 in glycemic control. Accordingly, increased ZFP36 expression in omental adipose tissue, but not in abdominal s.c. fat, may offer partial protection against the development of insulin resistance and diabetes.

\section{Acknowledgements}

This study was supported by operating funds from the Canadian Institutes of Health Research - Institute of Gender and Health to André Tchernof. Dr Luigi Bouchard is funded by the Nutraceuticals and Functional Foods Institute and the Heart and Stroke Foundation of Canada/Sanofi-Aventis through research fellowship awards. Dr Marie-Claude Vohl and Dr André Tchernof are research scholars from the Fonds de la Recherche en Santé du Québec (FRSQ) and the CIHR respectively. The contribution of Drs Philippe Laberge, Suzanne Noël, Jacques Mailloux, Denis Légaré, Céline Bouchard, Céline Huot, Michel Fortier, Johanne Hurtubise, and Pierre Dupont to the recruitment process of the study is gratefully acknowledged. The invaluable help of nurses Johanne Baillargeon, Danielle Bélanger, Francine Jobin, Nathalie Boulet, Céline Dugal, Fabienne Belleau, Monique Potvin, Diane Chamberland, Gisèle Gauvreau, Line Labbé, Paulo Lévesque, and of radiology technicians Suzanne Brulotte, Lyne Bargone, Linda Marcotte, Louise Mailloux, Diane Bastien, and Monique Caron is also acknowledged. We acknowledge the contribution of the Gene Quantification Core Laboratory of the Centre de Génomique de Québec. The authors wish to thank all women who participated in the study for their excellent collaboration.

\section{References}

1 Haslam DW \& James WP. Obesity. Lancet 2005366 1197-1209.

2 Després JP. Health consequences of visceral obesity. Annals of Medicine 200133 534-541. 
3 Kershaw EE \& Flier JS. Adipose tissue as an endocrine organ. Journal of Clinical Endocrinology and Metabolism $2004 \mathbf{8 9}$ 2548-2556.

4 Bouchard L, Tchernof T, Deshaies Y, Marceau S, Lescelleur O, Biron S \& Vohl M. ZFP 36: a promising candidate gene for obesityrelated metabolic complications identified by converging genomics. Obesity Surgery 200717 372-382.

5 Lai WS, Stumpo DJ \& Blackshear PJ. Rapid insulin-stimulated accumulation of an mRNA encoding a proline-rich protein. Journal of Biological Chemistry 1990265 16556-16563.

6 Taylor GA, Carballo E, Lee DM, Lai WS, Thompson MJ, Patel DD, Schenkman DI, Gilkeson GS, Broxmeyer HE, Haynes BF \& Blackshear PJ. A pathogenetic role for TNF alpha in the syndrome of cachexia, arthritis, and autoimmunity resulting from tristetraprolin (TTP) deficiency. Immunity 19964 445-454.

7 Carballo E, Lai WS \& Blackshear PJ. Feedback inhibition of macrophage tumor necrosis factor-alpha production by tristetraprolin. Science $1998 \mathbf{2 8 1} 1001-1005$.

8 Dandona P, Aljada A, Chaudhuri A, Mohanty P \& Garg R. Metabolic syndrome: a comprehensive perspective based on interactions between obesity, diabetes, and inflammation. Circulation 2005111 1448-1454.

9 Robitaille J, Despres JP, Perusse L \& Vohl MC. The PPAR-gamma P12A polymorphism modulates the relationship between dietary fat intake and components of the metabolic syndrome: results from the Quebec Family Study. Clinical Genetics 200363 109-116.

10 Deschenes D, Couture P, Dupont P \& Tchernof A. Subdivision of the subcutaneous adipose tissue compartment and lipid-lipoprotein levels in women. Obesity Research 200311 469-476.

11 Moorjani S, Dupont A, Labrie F, Lupien PJ, Brun D, Gagne C, Giguere $M$ \& Belanger A. Increase in plasma high-density lipoprotein concentration following complete androgen blockage in men with prostatic carcinoma. Metabolism 198736 244-250.

12 Gidez LI, Miller GJ, Burstein M, Slagle S \& Eder HA. Separation and quantitation of subclasses of human plasma high density lipoproteins by a simple precipitation procedure. Journal of Lipid Research 198223 1206-1223.

13 Matthews DR, Hosker JP, Rudenski AS, Naylor BA, Treacher DF \& Turner RC. Homeostasis model assessment: insulin resistance and beta-cell function from fasting plasma glucose and insulin concentrations in man. Diabetologia $1985 \mathbf{2 8} 412-419$.

14 Gabrielsson BG, Olofsson LE, Sjogren A, Jernas M, Elander A, Lonn M, Rudemo M \& Carlsson LM. Evaluation of reference genes for studies of gene expression in human adipose tissue. Obesity Research 200513 649-652.

15 Executive Summary of The Third Report of The National Cholesterol Education Program (NCEP) Expert Panel on Detection, Evaluation, And Treatment of High Blood Cholesterol In Adults (Adult Treatment Panel III). JAMA 2001285 2486-2497.
16 Després J \& Lamarche B. Effects of diet and physical activity on adiposity and body fat distribution: implications for the prevention of cardiovascular disease. Nutrition Research Reviews 19936 137-159.

17 Third Report of the National Cholesterol Education Program (NCEP) Expert Panel on Detection, Evaluation, and Treatment of High Blood Cholesterol in Adults (Adult Treatment Panel III) final report. Circulation $20021063143-3421$.

18 Vohl M, Sladek R, Robitaille J, Gurd S, Marceau P, Richard D, Hudson T \& Tchernof A. A survey of genes differentially expressed in subcutaneous and visceral adipose tissue in men. Obesity Research 200412 1217-1222.

19 Whittaker J, Okamoto AK, Thys R, Bell GI, Steiner DF \& Hofmann CA. High-level expression of human insulin receptor cDNA in mouse NIH 3T3 cells. PNAS $1987 \mathbf{8 4} 5237-5241$.

20 Trujillo ME \& Scherer PE. Adiponectin - journey from an adipocyte secretory protein to biomarker of the metabolic syndrome. Journal of Internal Medicine 2005257 167-175.

21 Lai WS, Thompson MJ, Taylor GA, Liu Y \& Blackshear PJ. Promoter analysis of Zfp-36, the mitogen-inducible gene encoding the zinc finger protein tristetraprolin. Journal of Biological Chemistry $199527025266-25272$.

22 Lai WS, Thompson MJ \& Blackshear PJ. Characteristics of the intron involvement in the mitogen-induced expression of Zfp-36. Journal of Biological Chemistry 1998273 506-517.

23 Carrick DM, Lai WS \& Blackshear PJ. The tandem CCCH zinc finger protein tristetraprolin and its relevance to cytokine mRNA turnover and arthritis. Arthritis Research and Therapy 20046 248-264.

24 Ruan H \& Lodish HF. Insulin resistance in adipose tissue: direct and indirect effects of tumor necrosis factor-alpha. Cytokine and Growth Factor Reviews 200314 447-455.

25 Dean JL, Sully G, Clark AR \& Saklatvala J. The involvement of AU-rich element-binding proteins in p38 mitogen-activated protein kinase pathway-mediated mRNA stabilisation. Cell Signalling 200416 1113-1121.

26 Maeda K, Okubo K, Shimomura I, Funahashi T, Matsuzawa Y \& Matsubara K. cDNA cloning and expression of a novel adipose specific collagen-like factor, apM1 (AdiPose Most abundant Gene transcript 1). Biochemical and Biophysical Research Communication $1996221286-289$.

27 Lihn AS, Pedersen SB \& Richelsen B. Adiponectin: action, regulation and association to insulin sensitivity. Obesity Reviews 20056 13-21.

Received 5 February 2007

Accepted 30 July 2007 